\title{
Chronic widespread pain and its associations with quality of life and function at a 20- year follow-up of individuals with chronic knee pain at inclusion
}

\author{
Stefan Bergman ${ }^{1,2,3}$, Carina Thorstensson ${ }^{3,4}$ and Maria L. E. Andersson ${ }^{2,3^{*}}$ (D)
}

\begin{abstract}
Objective: To study the prevalence of chronic widespread pain (CWP) and chronic regional pain (CRP), and their association to quality of life, pain, physical function at a 20-year follow-up in a population based cohort with chronic knee pain at inclusion.

Methods: 121 individuals (45\% women, mean age 64 years, range 54-73) with chronic knee pain from a population-based cohort study, answered a questionnaire and had radiographic knee examination at a 20-year follow-up. The responders were divided into three groups according to reported pain; individuals having no chronic pain (NCP), chronic widespread pain (CWP) and chronic regional pain (CRP). Pain and physical function were assessed using Knee injury and Osteoarthritis Outcome Score (KOOS). Health related quality of life (HRQL) was assessed with Euroqol-5D-3 L (EQ5D) and Short form 36 (SF36). The associations between pain groups and KOOS, EQ5D, and SF36 were analysed by multiple logistic regression, controlled for age, gender and radiographic changes indicating knee osteoarthritis $(\mathrm{OA})$.

Results: The prevalence of CWP was 30\%, and CWP was associated to worse scores in all KOOS subscales, controlled for age, gender and radiographic changes. CWP was also associated to worse scores in EQ-5D and in seven of the SF-36 subgroups, controlled for age, gender and radiographic changes.

Conclusion: One third of individuals with chronic knee pain met the criteria for CWP. CWP was associated with patient reported pain, function and HRQL. This suggest that it is important to assess CWP in the evaluation of patients with chronic knee pain, with and without radiographic knee OA.
\end{abstract}

Keywords: Knee osteoarthritis, Chronic widespread pain, Patient reported outcomes

\section{Introduction}

Pain is the most disabling symptom of osteoarthritis (OA), resulting in disability and inactivity, and a common reason to search medical care. Several studies have shown associations between $\mathrm{OA}$ and fibromyalgia, with a fibromyalgia prevalence of 5 to $10 \%$ in individuals with OA compared

\footnotetext{
* Correspondence: maria.andersson@fou-spenshult.se

${ }^{2}$ Department of Clinical Sciences, Rheumatology, Lund University, Lund, Sweden

${ }^{3}$ Spenshult Research and Development Center, Bäckagårdsvägen 47, SE-302

74 Halmstad, Sweden

Full list of author information is available at the end of the article
}

to 1 to $5 \%$ in the general population [1-5]. The overall prevalence of chronic widespread pain in the general population is estimated to $10 \%$ [6].

Although the association between radiographic knee OA and reported pain has shown to be weak [7], there is an association between presence of pain and synovitis, bone marrow oedema, and bone marrow lesions [8]. Associations have also been seen between radiographic severity, assessed with Kellgren \& Lawrence score, and Western Ontario and McMaster Universities Osteoarthritis Index (WOMAC)

(c) The Author(s). 2019 Open Access This article is distributed under the terms of the Creative Commons Attribution 4.0 International License (http://creativecommons.org/licenses/by/4.0/) which permits unrestricted use, distribution, and reproduction in any medium, provided you give appropriate credit to the original author(s) and the source, provide a link to the Creative Commons license, and indicate if changes were made. The Creative Commons Public Domain Dedication waiver (http://creativecommons.org/publicdomain/zero/1.0/) applies to the data made available in this article, unless otherwise stated. 
pain score, especially with regard to OA severity in the patellofemoral compartment [9].

There is evidence for shared pain mechanisms in OA and fibromyalgia [10]. Pain in OA is thought to be associated to an increased excitability of both peripheral and central pain pathways, which in the end could cause sensitization and an increased risk of widespread pain [10-12]. Studies of pain trajectories in knee OA have identified a group of individuals with severe pain, not improving over time, which could represesent a group with a more chronic widespread pain [13, 14].

Chronic widespread pain (CWP) and fibromyalgia (FM) are common in other musculoskeletal diseases, as for example rheumatoid arthritis (RA), spondylarthritis (SpA), systemic lupus erythematosus (SLE) and polymyalgia rheumatica. CWP has substantial impact on measures of disease activity, function, and pain [1, 15-18].

In studies of knee OA, knee-related patient reported outcomes such as Knee injury and Osteoarthritis Outcome Score (KOOS) [19] and WOMAC [20], together with measures of quality of life, such as Short form 36 (SF36), are recommended [21]. These knee related outcomes are also used in clinical settings, to assess the patient's perspective of their knee associated problems. KOOS and WOMAC are designed to measure local pain and physical discomfort from, for example, the knees, but also patients with knee OA and a concurrent fibromyalgia have been reported to have a worse score on WOMAC [2]. Other factors, that have been reported to influence KOOS, are age and gender $[21,22]$. The knowledge of how other factors, for example CWP, influence these knee related scores recommended to use as core outcome in OA trials are lacking.

The objective was to study the prevalence of chronic widespread pain (CWP) and chronic regional pain (CRP), and their association to pain, physical function and quality of life as measured by KOOS, EQ5D and SF36, in a 20-year follow-up of a population-based cohort with chronic knee pain at inclusion.

\section{Method}

\section{Participants}

This cross-sectional study included 121 individuals that in 2010 participated in a 20-year follow-up of a longitudinal population-based cohort, that at baseline included 183 individuals with knee pain. In 2010 there were 156 individuals eligible for the 20-year follow-up [23] [23]. The 20-year follow-up included a questionnaire and a radiographic knee examination.

\section{Questionnaire}

Pain was reported by a pain mannequin (a figure with 18 predefined body regions) [24]. Pain duration for at least three months was designated as chronic. Chronic widespread pain
(CWP) was defined according to the ACR 1990 criteria for fibromyalgia [25], requiring pain in both sides of the body, in upper and lower body, and in the axial skeleton. Those with chronic pain, but not fulfilling criteria for CWP were considered as having chronic regional pain (CRP). Individuals with pain duration shorter than three months were categorised as having no chronic pain (NCP). The questionnaire included the Knee injury and Osteoarthritis Outcome Score (KOOS) consisting of 5 subscales, range 0-100 (best to worse); Pain (KOOS-Pain), other Symptoms (KOOSSymptom), Function in daily living (KOOS-ADL), Function in sport and recreation (KOOS-Sport/Rec) and knee related Quality of life (KOOS-QOL) [19, 26]. Health related quality of life was assessed by the Euroqol-5D-3 L (EQ5D) questionnaire and the 36-item short form survey (SF36). The EQ5D questionnaire, range 0-1 (worse to best), includes five questions about mobility, self-care, usual activities pain/discomfort, anxiety/depression, each of which can take one of three responses [27]. The SF36 questionnaire, range 0-100 (worse to best), assess qualityof-life in eight health concepts: physical functioning (SF36-PF), role physical (SF36-RP), bodily pain (SF36-BP), general health (SF36-GH), vitality (SF36-VT), social functioning (SF36-SF), role emotional (SF36-RE), mental health (SF36-MH) [28, 29].

\section{Radiographic examination}

The radiographs were obtained in a skyline view of patellofemoral (PF) joints, and posteroanterior radiographs of both TF joints were obtained in weightbearing position using a fluoroscopy unit. The patients stood with almost their entire weight on the leg being examined, with the knee flexed $30-50^{\circ}$, and with the patella and the big toe touching the table of the fluoroscopy unit. Radiographic osteoarthritis (OA) was defined as joint space width (JSW) $<3 \mathrm{~mm}$ in the tibiofemoral compartment and/or JSW $<5 \mathrm{~mm}$ in the patellofemoral compartment. Tibiofemoral knee OA (TFOA) was defined as JSW $<3 \mathrm{~mm}$ in the tibiofemoral compartment and patellofemoral knee OA (PFOA) as JSW $<5 \mathrm{~mm}$ in the patellofemoral compartment [30,31]. Osteophytes in both compartments were scored according to Ahlbäck [32]. Fifteen individuals were not having the radiographic examination, two had total knee replacement in both knees, and the other 13 were not able to get to the examination due to work or long travel distance.

\section{Statistics}

Statistical analyses were performed using SPSS Statistics 21 software. All tests were two tailed and conducted at the 0.05 significance level. Chi-square test was used to test for differences in proportions between groups. Kruskal-Wallis with post hoc pairwise analysis was used for continuous variables when comparing more than two 
groups, and Mann-Whitney when comparing two groups, due to that some of the variables were not normally distributed. Correlations were performed by the Spearman's test. Multiple logistic regression analyses were used to study the associations between pain groups and being in the worse half, according to median value, of KOOS, EQ-5D and SF36 at 20 years follow-up, respectively, controlled for age, gender and having or not having radiographic knee $\mathrm{OA}$.

\section{Results}

Thirty-five individuals rejected participation, with no significant difference in age, gender distribution or (body mass index) BMI compared to the participants. The participants were $45 \%$ women, mean age was 64 years with a range between 54 and 73 years and mean BMI was
$27.9 \mathrm{~kg} / \mathrm{m} 2$ with a range between 19.2 and $45.0 \mathrm{~kg} / \mathrm{m} 2$, where $75 \%$ had $\mathrm{BMI}>25 \mathrm{~kg} / \mathrm{m} 2$.

\section{Prevalence of chronic widespread pain}

Thirty percent of the included individuals reported CWP $(n=36), 48 \%(n=58)$ CRP and, 22\% $(n=27)$ NCP. Six percent reported that they had been diagnosed with fibromyalgia (FM). There was no significant difference in age or BMI between the pain groups, Table 1 . There were more women in the CWP group compared to the CRP group. Forty-nine (41\%) of those participating in the 20-year follow-up reported knee pain in at least one knee, and of those 7 (6\% of all participants) reported knee pain only.

\section{Pain, radiographic features and BMI}

There was no statistically significant difference in the rate of radiographic OA between the groups with $\mathrm{NCP}$,

Table 1 Descriptives of the three pain groups, and between group differences at 20-year follow-up

\begin{tabular}{|c|c|c|c|c|c|}
\hline & $\begin{array}{l}\text { All } \\
\text { Mean }(95 \% \text { Cl) }\end{array}$ & $\begin{array}{l}\text { NCP } \\
\text { Mean (95\% Cl) }\end{array}$ & $\begin{array}{l}\text { CRP } \\
\text { Mean }(95 \% \text { Cl) }\end{array}$ & $\begin{array}{l}\text { CWP } \\
\text { Mean }(95 \% \text { Cl) }\end{array}$ & $P$-value \\
\hline$N(\%)$ & 121 & $28(23)$ & $57(47)$ & $36(30)$ & \\
\hline Age & $64(63-65)$ & $63(61-65)$ & $64(62-65)$ & $63(61-65)$ & 0.904 \\
\hline Women \% & 45 & 54 & 33 & 56 & 0.061 \\
\hline BMI $\left(\mathrm{kg} / \mathrm{m}^{2}\right)$ & $27.9(27.1-28.7)$ & 26.9 (25.2-28.4) & $27.9(26.9-28.9)$ & $28.8(26.8-30.8)$ & 0.521 \\
\hline Painful regions (0-18) & $3.8(3.1-4.4)$ & $0(0-0)$ & $2.9(2.4-3.4)$ & $8.1(7.0-9.1)$ & $<0.001$ \\
\hline Knee pain (\%) & 40 & 0 & 35 & 81 & $<0.001$ \\
\hline Knee OA (\%) & 51 & 44 & 52 & 55 & 0.707 \\
\hline TFOA (\%) & 17 & 12 & 14 & 26 & \\
\hline PFOA (\%) & 29 & 32 & 30 & 26 & $0.535^{\mathrm{a}}$ \\
\hline TFPFOA (\%) & 5 & 0 & 8 & 3 & \\
\hline Osteophytes (\%) & 91 & 88 & 94 & 90 & 0.664 \\
\hline KOOS-pain (0-100) & $72.8(68.9-76.8)$ & $84.8(78.0-91.6)$ & $74.2(68.2-80.3)$ & $61.6(55.4-67.8)$ & $<0.001$ \\
\hline KOOS-symptom (0-100) & $74.3(70.8-77.9)$ & $85.2(80.8-89.6)$ & $75.0(69.5-80.5)$ & $65.2(58.7-71.7)$ & $<0.001$ \\
\hline KOOS-ADL (0-100) & 76.7 (73.0-80.4) & $88.3(82.2-94.4)$ & $78.5(73.3-83.7)$ & $65.1(58.6-71.6)$ & $<0.001$ \\
\hline KOOS-Sport/Rec (0-100) & $49.8(43.9-55.7)$ & $65.4(53.5-77.3)$ & $52.0(42.8-61.2)$ & $35.3(26.7-43.8)$ & $<0.001$ \\
\hline KOOS-QOL (0-100) & $60.9(56.3-65.5)$ & $76.4(68.4-84.5)$ & $63.0(56.2-69.7)$ & $46.5(39.6-53.5)$ & $<0.001$ \\
\hline EQ5D (0-1) & $0.75(0.71-0.79)$ & $0.90(0.85-0.95)$ & $0.74(0.69-0.78)$ & $0.63(0.54-0.72)$ & $<0.001$ \\
\hline SF36-PF (0-100) & 72.7 (68.6-76.8) & $87.1(81.8-92.5)$ & $72.1(66.2-78.0)$ & $62.3(54.4-70.1)$ & $<0.001$ \\
\hline SF36-RP (0-100) & $65.0(57.7-72.3)$ & $89.8(80.2-99.4)$ & $61.3(50.4-72.3)$ & $51.4(37.2-65.7)$ & $<0.001$ \\
\hline SF36-BP (0-100) & $56.2(51.9-60.5)$ & 83.8 (75.9-91.8) & $52.1(47.3-56.8)$ & $42.1(36.4-47.8)$ & $<0.001$ \\
\hline SF36-GH (0-100) & $66.0(61.9-70.1)$ & $75.6(69.2-82.0)$ & $68.9(63.1-74.7)$ & $53.3(45.4-61.1)$ & $<0.001$ \\
\hline SF36-VT (0-100) & $63.1(58.6-67.5)$ & $75.0(67.2-82.7)$ & $64.3(58.8-70.2)$ & $52.5(43.6-61.5)$ & 0.002 \\
\hline SF36-SF (0-100) & $85.6(81.7-89.6)$ & 93.5 (87.2-99.9) & 87.5 (83.1-91.9) & 76.7 (66.9-86.6) & 0.018 \\
\hline SF36-RE (0-100) & $80.4(73.8-87.0)$ & $85.9(73.8-98.0)$ & $84.6(75.7-93.5)$ & $70.4(56.2-84.6)$ & 0.232 \\
\hline SF36-MH (0-100) & 79.9 (76.7-83.0) & 86.5 (80.0-92.9) & $81.6(77.5-85.8)$ & $72.2(65.9-78.5)$ & 0.001 \\
\hline
\end{tabular}

NCP No chronic pain, CRP chronic regional pain, CWP chronic widespread pain, BMI body mass index, TFOA radiographic tibiofemoral osteoarthritis, $P F O A$ radiographic patellofemoral osteoarthritis, TFPFOA radiographic tibio- and patellofemoral osteoarthritis, OA osteoarthritis, TF tibiofemoral, $P F$ patellofemoral, TFPF tibio- and patellofemoral, $A D L$ activity of daily living, Sport/rec function in sport and recreation, $Q O L$ knee related Quality of life, $P F$ physical function, $R P$ rolephysical, $B P$ bodily pain, $G H$ general health, $V T$ vitality, $S F$ social functioning, $R E$ role-emotional, $M H$ mental health a overall p-value, chi ${ }^{2}$-test 
CRP or CWP, neither in the presence of osteophytes or in mean BMI between the groups, Table 1. In total 27\% of the participants were obese, though there were no statistically significant difference between the groups (NCP 16\%, CRP 31\% and CWP 29\%). There were no associations between CWP, radiographic OA (OR 1.122, 95\% CI $0.468-2.691$ ), osteophytes (OR 0.864, 95\% CI 0.1983.770) or BMI (OR 1.062, 95\% CI 0.960-1.174), controlled for age and gender.

\section{Pain groups and KOOS}

Individuals reporting CWP had worse KOOS-pain compared to those with NCP and CRP, $(p<0.001$ and $p=$ $0.005)$, worse KOOS-symptom $(p=0.001$ and $p=0.012)$, worse KOOS-ADL $(\mathrm{p}<0.001$ and $p=0.002)$, worse KOOS-sport/rec $(\mathrm{p}<0.001$ and $P=0.008)$ and worse KOOS-QOL $(\mathrm{p}<0.001$ and $p=0.004)$, Table 1 and Fig. 1 .

In a multiple logistic regression analysis, CWP was associated to being in the worse half of all subgroups of KOOS (pain, symptom, ADL, sport/rec and QOL) controlled for age, gender and radiographic knee OA, Table 2. Having radiographic knee $\mathrm{OA}$ was also associated to being in the worse half of all KOOS subscales, Table 2.

\section{Pain groups and health-related quality of life}

Individuals reporting CWP had worse EQ5D compared to those reporting both CRP and CWP $(p<0.001$ and $p=0.027)$. CWP was associated to being in the worse half of EQ5D (OR 14.6, 95\% CI 3.5-61.0), controlled for age, gender and radiographic knee OA.

Individuals reporting CWP had worse SF36 than those reporting NCP in the subscales PF $(\mathrm{p}<0.001), \mathrm{RP}(\mathrm{p}<$ $0.001)$, BP $(\mathrm{p}<0.001), \mathrm{GH}(p=0.001)$, VT $(p=0.002), \mathrm{SF}$ $(p=0.014)$, and $\mathrm{MH}(\mathrm{p}=0.001)$, Table 1 and Fig. 2 . In the two subscales, $\mathrm{GH}$ and $\mathrm{MH}$, individuals reporting CWP also had a worse score than those with CRP (GH $p=0.009$, $\mathrm{MH} p=0.035)$, Table 1 and Fig. 2. There was no significant difference between the groups in the subscale RE.

In multiple logistic regression analyses associations were found between CWP and worse scores in seven of the subgroups of SF-36 (PF, RP, BP, GH, VT, SF, MH), controlled for age, gender and radiographic knee OA, Table 3.

\section{Discussion}

In this cross-sectional study of individuals with knee pain at inclusion, one third reported CWP at a 20-year follow-up, regardless of having radiographic knee OA or not. The presence of CWP was associated to worse outcome in KOOS, SF36 and EQ5D.

There are no comparable studies on OA and CWP, but studies in the general population have reported a prevalence of CWP between 11 and 13\% [3, 33, 34], with an overall prevalence in the world of $10 \%$ [6]. In RA the prevalence of CWP has been reported to be in the same order as for OA in this study, about 30\% [15].

In the present study $6 \%$ reported that they had fibromyalgia, which is somewhat lower than previously reported in patients with OA [2], but higher than the prevalence in the general population, reported to be between 1 to $5 \%$ [3-5]. The difference could depend on that the diagnose was self-reported in the present study and not evaluated by clinical examination [2]. The prevalence of fibromyalgia is also increased compared to general population in other rheumatic diseases. For example, in SLE and AS about 13\% are fulfilling the criteria for fibromyalgia and in Sjögrens syndrome about $12 \%$ [2].

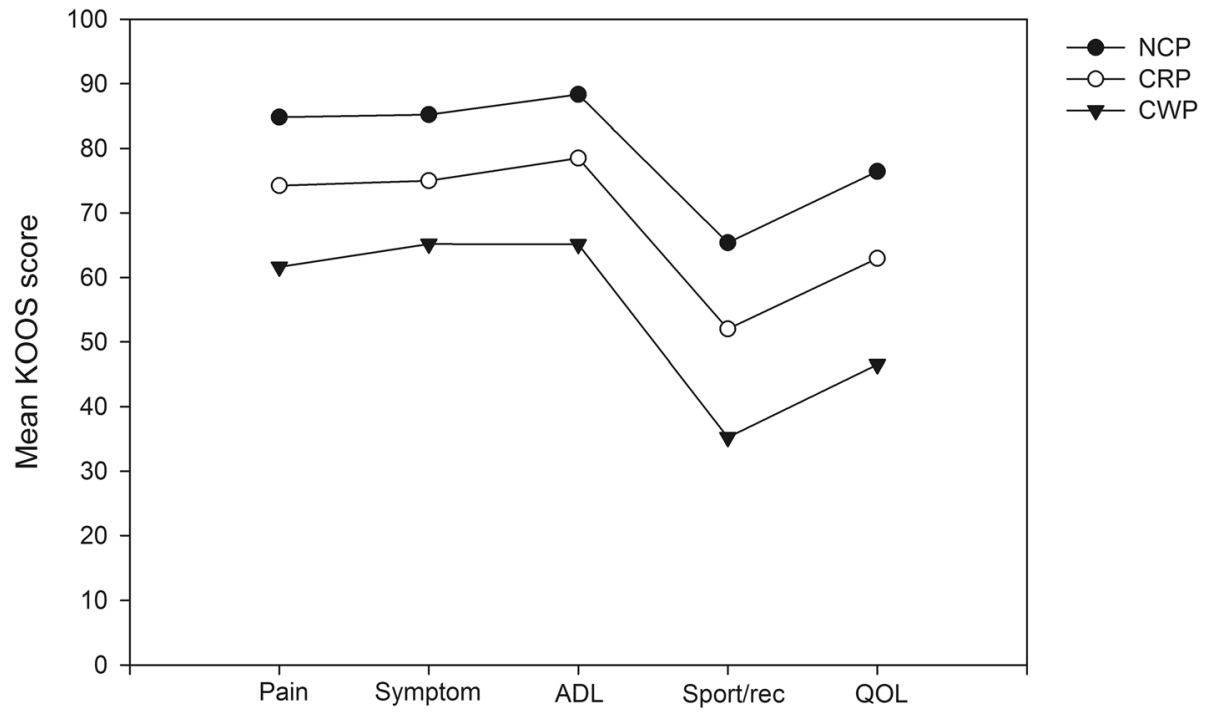

Fig. 1 Mean KOOS score in the three groups; NCP, no chronic pain; CRP, chronic regional pain and CWP, chronic widespread pain at 20-year follow-up in individuals with chronic knee pain at inclusion 
Table 2 Associations between being in the worse half of KOOS subscales and the different pain groups controlled for age, gender and having or not having radiographic knee OA at 20-year follow-up in a cohort with chronic knee pain at inclusion

\begin{tabular}{|c|c|c|c|c|c|c|c|c|c|c|}
\hline & \multicolumn{2}{|c|}{ KOOS Pain } & \multicolumn{2}{|c|}{ KOOS Symptom } & \multicolumn{2}{|c|}{ KOOS ADL } & \multicolumn{2}{|c|}{ KOOS Sport/Rec } & \multicolumn{2}{|c|}{ KOOS QOL } \\
\hline & $\overline{\mathrm{OR}}$ & $95 \% \mathrm{Cl}$ & $\overline{O R}$ & $95 \% \mathrm{Cl}$ & $\overline{O R}$ & $95 \% \mathrm{Cl}$ & $\overline{\mathrm{OR}}$ & $95 \% \mathrm{Cl}$ & OR & $95 \% \mathrm{Cl}$ \\
\hline Age & 1.003 & $0.929-1.082$ & 0.974 & $0.899-1.055$ & 1.015 & $0.936-1.099$ & 1.021 & $0.947-1.100$ & 0.993 & $0.917-1.076$ \\
\hline Gender (women) & 0.716 & $0.296-1.733$ & 0.679 & $0.268-1.724$ & 0.685 & $0.269-1.749$ & 0.597 & $0.245-1.453$ & 0.421 & $0.159-1.117$ \\
\hline Knee OA & 2.431 & $1.008-5.865$ & 3.804 & $1.483-9.761$ & 2.917 & $1.148-7.414$ & 3.075 & $1.279-7.396$ & 3.938 & $1.498-10.353$ \\
\hline NCP & 1 & & 1 & & 1 & & 1 & & 1 & \\
\hline CRP & 2.088 & $0.686-6.355$ & 3.342 & $0.943-11.842$ & 2.612 & $0.809-8.432$ & 1.894 & $0.627-5.722$ & 3.191 & $0.880-11.568$ \\
\hline CWP & 6.379 & $1.877-21.676$ & 11.958 & $3.002-47.584$ & 17.295 & $4.332-69.052$ & 3.522 & $1.063-11.666$ & 11.300 & $2.769-46.107$ \\
\hline
\end{tabular}

$A D L$ activity of daily living, Sport/Rec sport and recreation function, $Q O L$ knee-related quality of life, CRP chronic regional pain, CWP chronic widespread pain, Knee $O A$ having radiographic knee osteoarthritis

In this study, no associations between CWP and radiographic changes were found, neither when assessed by joint space width or by osteophytes. There have been divergent results when studying the association between pain, radiographic OA and osteophytes, [35-38]. Though, a study by Finan et al. reported that central sensitization was more frequently present in patients, who reported a high level of clinical pain in the absence of moderate-tosevere radiographic knee OA [7].

In the present study there was no difference in BMI between the three pain groups, although there was a numerically higher rate of obesity in the CRP and CWP groups than in the NCP group. A study from the Osteoarthritis Initiative has shown that individuals with higher BMIs reported more pain than individuals with lower BMIs [39].

Individuals reporting CWP had worse KOOS in all subscales compared to those not reporting any chronic widespread pain. In KOOS, all subscales were associated to both knee OA and chronic widespread pain, with the highest association between CWP and activity of daily living. Another study has shown similar finding in individuals with OA and fibromyalgia reporting worse WOMAC compared to individuals with $\mathrm{OA}$ without fibromyalgia [2]. Individuals reporting NCP had better health-related quality of life than both CRP and CWP and that is in line with results from other studies [40, 41]. Pain is probably one of the most important factors affecting function, wellbeing and health-related quality of life regardless of the chronic disease [42-44]. The association between patient reported outcome in rheumatic disorders and chronic widespread pain is well known. Disease specific measurements, such as 28-joints Disease Activity Score (DAS28) for rheumatoid arthritis (RA) and Bath Ankylosing Spondylitis Disease Activity Index (BASDAI) for ankylosing spondylitis (AS), have also been shown to be influenced by fibromyalgia or CWP, were patients with fibromyalgia or CWP reported worse disease activity $[2,15,17]$. Pain affects patients' perception of function and well-being significantly. In both clinic and research, when using knee specific assessments as KOOS and WOMAC, the

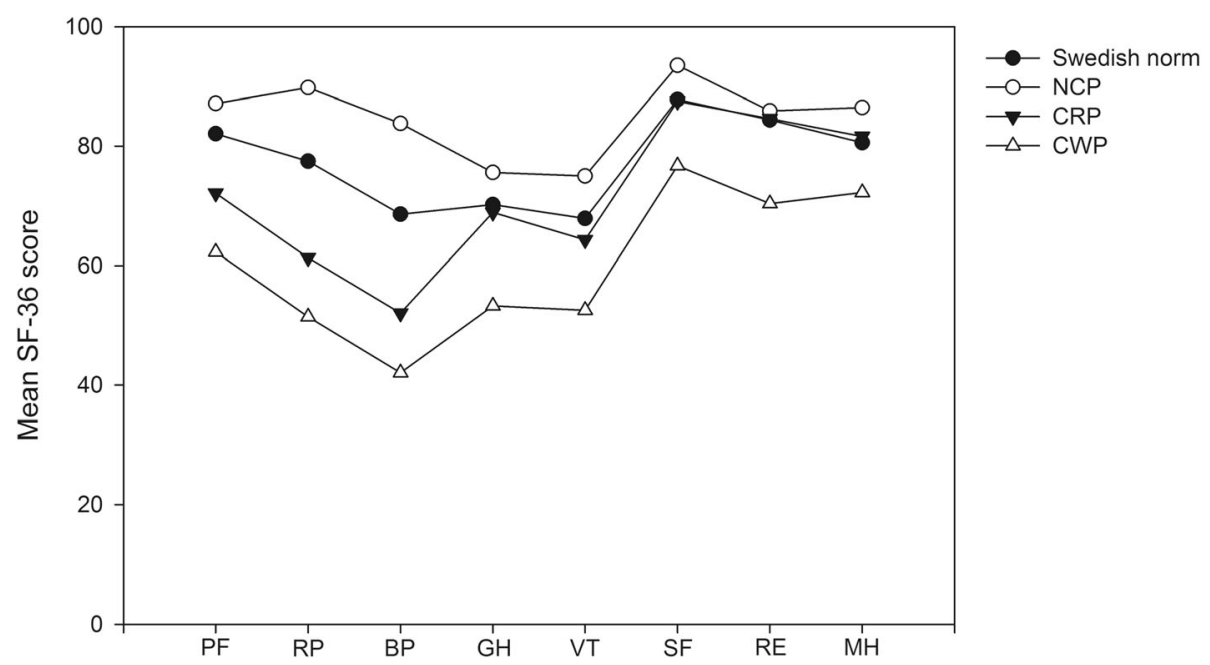

Fig. 2 Mean SF-36 score in the three groups; NCP, no chronic pain; CRP, chronic regional pain and CWP, chronic widespread pain at 20-year follow-up of individuals with chronic knee pain at inclusion. Swedish norm from Sullivan et al., 2002 [28] 
Table 3 Associations between being in the worse half of SF-36 subscales and the different pain groups controlled for age, gender and having or not having radiographic knee OA at 20-year follow-up in a cohort with chronic knee pain at inclusion

\begin{tabular}{|c|c|c|c|c|c|c|c|c|}
\hline & \multicolumn{2}{|c|}{ SF-36 PF } & \multicolumn{2}{|c|}{ SF-36 RP } & \multicolumn{2}{|c|}{ SF-36 BP } & \multicolumn{2}{|c|}{ SF-36 GH } \\
\hline & $\mathrm{OR}$ & $95 \% \mathrm{Cl}$ & $\mathrm{OR}$ & $95 \% \mathrm{Cl}$ & OR & $95 \% \mathrm{Cl}$ & OR & $95 \% \mathrm{Cl}$ \\
\hline Age & 1.098 & $1.014-1.189$ & 1.031 & $0.952-1.115$ & 0.962 & $0.886-1.044$ & 1.041 & $0.962-1.126$ \\
\hline Gender (Women) & 1.542 & $0.618-3.845$ & 0.840 & $0.339-2.084$ & 1.238 & $0.476-3.220$ & 0.688 & $0.275-1.723$ \\
\hline Knee OA & 1.536 & $0.627-3.764$ & 1.420 & $0.581-3.471$ & 0.883 & $0.344-2.264$ & 1.064 & $0.434-2.613$ \\
\hline NCP & 1 & & 1 & & 1 & & 1 & \\
\hline CRP & 4.080 & $1.248-13.342$ & 7.736 & $2.153-25.269$ & 20.056 & $4.071-98.795$ & 2.370 & $0.792-6.234$ \\
\hline \multirow[t]{3}{*}{ CWP } & 9.391 & $2.491-35.400$ & 11.654 & $2.854-41.544$ & 45.482 & 6.413-185.387 & 13.348 & $3.467-51.396$ \\
\hline & \multicolumn{2}{|c|}{ SF-36 VT } & \multicolumn{2}{|c|}{ SF-36 SF } & \multicolumn{2}{|c|}{ SF-36 RE } & \multicolumn{2}{|c|}{ SF-36 MH } \\
\hline & OR & $95 \% \mathrm{Cl}$ & OR & $95 \% \mathrm{Cl}$ & OR & $95 \% \mathrm{Cl}$ & OR & $95 \% \mathrm{Cl}$ \\
\hline Age & 1.005 & $0.933-1.082$ & 1.014 & $0.943-1.091$ & 0.996 & $0.918-1.081$ & 1.095 & $1.008-1.190$ \\
\hline Gender (women) & 1.208 & $0.513-2.844$ & 0.750 & $0.320-1.759$ & 1.223 & $0.483-3.095$ & 2.140 & $0.837-5.470$ \\
\hline Knee OA & 0.887 & $0.378-2.081$ & 1.049 & $0.452-2.438$ & 1.540 & $0.597-3.971$ & 1.284 & $0.512-3.217$ \\
\hline NCP & 1 & & 1 & & 1 & & 1 & \\
\hline CRP & 3.707 & $1.171-11.741$ & 2.608 & $0.831-8.190$ & 1.089 & $0.322-3.681$ & 4.260 & $1.292-14.044$ \\
\hline CWP & 6.560 & $1.897-22.686$ & 4.036 & $1.196-13.612$ & 2.235 & $0.648-7.705$ & 12.238 & $3.131-47.830$ \\
\hline
\end{tabular}

$P F$ physical function, $R P$ role physical, $B P$ bodily pain, $G H$ general health, $V T$ vitality, $S F$ social functioning, $R E$ role emotional, $M H$ mental health, $C R P$ chronic regional pain, CWP chronic widespread pain, Knee $O A$ having radiographic knee osteoarthritis

interpretation is that it is the knee problems that is measured, although it is common to have pain elsewhere as well. The minimum clinically important difference (MCID) reported for KOOS is $\geq 20$ [45]. The difference between the NCP and the CWP group in all subscales are $\geq 20$. The minimal important change (MIC) is suggested to be $8-10$ in all subscales [46]. The differences between the groups in this study are above MIC in all subscales. Since there are differences between groups that are above MIC and in some cases above MCID, CWP could be considered to affect KOOS in a clinically relevant way. A clinical implication of this could be that even if you treat the knee symptoms, it may not have a substantial effect on the proposed knee related scores due to that pain in other sites also has an impact on the score. When using these instruments for assessing disease activity both in clinical practise and in research it is important to assess and be aware of that generalized pain is a common coexisting phenomenon. One way to investigate if the patient has pain in other sites could be to ask the patient in a structured way and document it or to ask the patient to fill in a pain mannequin and take the results in to account when evaluating the results from KOOS. From a clinical point of view it is also important to identify individuals with knee pain and a concomitant CWP, since they may need a more complex intervention [47].

[40-44]The cross-sectional design is a limitation that precludes assessment of causal relationships. The study is based on data collected in 2010, which could be considered to be a limitation due to time. However, the association between knee pain and CWP could still be considered to be important and relevant when assessing knee pain in the clinic.

\section{Conclusion}

One third of individuals with chronic knee pain met the criteria for CWP. CWP was associated with patient reported pain, function and health-related quality of life. This suggest that it is important to assess CWP in the evaluation of patients with chronic knee pain with and without radiographic knee $\mathrm{OA}$, when evaluating knee related outcomes in research and clinical settings.

\section{Abbreviations}

ADL: Function in daily living; AS: Ankylosing spondylitis; BASDI: Bath Ankylosing Spondylitis Disease Activity Index; BMI: Body mass index; BP: Bodily pain; CRP: Chronic regional pain; CWP: Chronic widespread pain; DAS28: 28-joints Disease activity index; EQ-5D: Euroqol 5D-3 L;

FM: Fibromyalgia; GH: General health; HRQL: Health related quality of life; JSW: Joint space width; KOOS: Knee injury and Osteoarthritis Outcome Score; $\mathrm{MH}$ : Mental health; NCP: No chronic pain; OA: Osteoarthritis; PF: Physical functioning; PFOA: Patellofemoral osteoarthritis; QOL: Knee related Quality of life; RA: Rheumatoid arthritis; RE: Role emotional; RP: Role physical; SF: Social functioning; SF36: Short form 36; Sport/rec: Function in sport and recreation; TFOA: Tibiofemoral osteoarthritis; VT: Vitality

\section{Acknowledgements}

The authors acknowledge Ingemar F Petersson, who initiated the cohort Some preliminary results was presented at the EULAR congress in 2015 [48]. Open access funding provided by Lund University.

\section{Ethical considerations}

Ethical approval was obtained from the Regional Ethical Review Board at Lund University, Lund, Sweden, at study start (LU 312-90). The study followed the guidelines from the Helsinki Declaration. Written consent from the participants was obtained. 


\section{Availability of data and material}

The datasets generated and/or analysed during the current study are not publicly available due to individual privacy but are available from the corresponding author on reasonable request.

\section{Authors' contributions}

SB participated in planning the study design, participated in statistical analyses and interpretation of the data and drafted the manuscript. CT participated in planning the study design, data interpretation, helped draft and critically revised the manuscript. MA participated in planning the study design, gathered the data from the database, participated in statistical analysis, data interpretation and critically revised the manuscript. All authors read and approved the final manuscript.

\section{Authors' information}

$\mathrm{SB}$ is $\mathrm{MD}$ and professor at University of Gothenburg, specialized in chronic pain. CT is PT and associate professor at University of Gothenburg, specialized in knee OA. MA is BMsc, PhD and senior researcher, with knowledge of chronic pain in rheumatic diseases.

\section{Funding}

The study was funded by the Regional board of Southern Sweden research fund and the Swedish Rheumatism Association. The funding associations have not had any other role in the study.

\section{Consent for publication}

All individuals involved in this study provided written consent to use their clinical and imaging data for research purposes.

\section{Competing interests}

The authors declare no conflict of interest.

\section{Author details}

${ }^{1}$ Primary Health Care Unit, Department of Public Health and Community Medicine, Institute of Medicine, The Sahlgrenska Academy, University of Gothenburg, Gothenburg, Sweden. ${ }^{2}$ Department of Clinical Sciences, Rheumatology, Lund University, Lund, Sweden. ${ }^{3}$ Spenshult Research and Development Center, Bäckagårdsvägen 47, SE-302 74 Halmstad, Sweden. ${ }^{4}$ Department of Clinical Neuroscience and RehabilitationThe Sahlgrenska Academy, Institute of Neuroscience and Physiology, University of Gothenburg, Gothenburg, Sweden.

\section{Received: 5 April 2019 Accepted: 28 November 2019}

\section{Published online: 09 December 2019}

\section{References}

1. Bliddal H, Danneskiold-Samsoe B. Chronic widespread pain in the spectrum of rheumatological diseases. Best Pract Res Clin Rheumatol. 2007;21:391-402.

2. Haliloglu S, Carlioglu A, Akdeniz D, Karaaslan Y, Kosar A. Fibromyalgia in patients with other rheumatic diseases: prevalence and relationship with disease activity. Rheumatol Int. 2014;34:1275-80.

3. Lindell L, Bergman S, Petersson IF, Jacobsson LT, Herrstrom P. Prevalence of fibromyalgia and chronic widespread pain. Scand J Prim Health Care. 2000; 18:149-53.

4. Branco JC, Bannwarth B, Failde I, Abello Carbonell J, Blotman F, Spaeth M, et al. Prevalence of fibromyalgia: a survey in five European countries. Semin Arthritis Rheum. 2010;39:448-53.

5. Jones GT, Atzeni F, Beasley M, Fluss E, Sarzi-Puttini P, Macfarlane GJ. The prevalence of fibromyalgia in the general population: a comparison of the American College of Rheumatology 1990, 2010, and modified 2010 classification criteria. Arthritis Rheumatol. 2015;67:568-75.

6. Andrews $P$, Steultjens M, Riskowski J. Chronic widespread pain prevalence in the general population: a systematic review. Eur J Pain. 2018;22:5-18.

7. Finan PH, Buenaver LF, Bounds SC, Hussain S, Park RJ, Haque UJ, et al. Discordance between pain and radiographic severity in knee osteoarthritis: findings from quantitative sensory testing of central sensitization. Arthritis Rheum. 2013;65:363-72.

8. Szebenyi B, Hollander AP, Dieppe P, Quilty B, Duddy J, Clarke S, et al. Associations between pain, function, and radiographic features in osteoarthritis of the knee. Arthritis Rheum. 2006;54:230-5.
9. Duncan R, Peat G, Thomas E, Wood L, Hay E, Croft P. How do pain and function vary with compartmental distribution and severity of radiographic knee osteoarthritis? Rheumatology (Oxford). 2008;47:1704-7.

10. Staud R. Evidence for shared pain mechanisms in osteoarthritis, low back pain, and fibromyalgia. Curr Rheumatol Rep. 2011;13:513-20.

11. Arendt-Nielsen L, Nie $H$, Laursen MB, Laursen BS, Madeleine $P$, Simonsen $\mathrm{OH}$, et al. Sensitization in patients with painful knee osteoarthritis. Pain. 2010;149:573-81.

12. Gwilym SE, Keltner JR, Warnaby CE, Carr AJ, Chizh B, Chessell I, et al. Psychophysical and functional imaging evidence supporting the presence of central sensitization in a cohort of osteoarthritis patients. Arthritis Rheum. 2009;61:1226-34.

13. Bastick AN, Wesseling J, Damen J, Verkleij SP, Emans PJ, Bindels PJ, et al. Defining knee pain trajectories in early symptomatic knee osteoarthritis in primary care: 5-year results from a nationwide prospective cohort study (CHECK). Br J Gen Pract. 2016;66:e32-9.

14. Nicholls E, Thomas E, van der Windt DA, Croft PR, Peat G. Pain trajectory groups in persons with, or at high risk of, knee osteoarthritis: findings from the knee clinical assessment study and the osteoarthritis initiative. Osteoarthr Cartil. 2014;22:2041-50.

15. Andersson ML, Svensson B, Bergman S. Chronic widespread pain in patients with rheumatoid arthritis and the relation between pain and disease activity measures over the first 5 years. J Rheumatol. 2013;40:1977-85.

16. Leeb BF, Andel I, Sautner J, Nothnagl T, Rintelen B. The DAS28 in rheumatoid arthritis and fibromyalgia patients. Rheumatology (Oxford). 2004;43:1504-7.

17. Heikkila S, Ronni S, Kautiainen HJ, Kauppi MJ. Functional impairment in spondyloarthropathy and fibromyalgia. J Rheumatol. 2002;29:1415-9.

18. Middleton GD, McFarlin JE, Lipsky PE. The prevalence and clinical impact of fibromyalgia in systemic lupus erythematosus. Arthritis Rheum. 1994;37:1181-8.

19. Roos EM, Roos HP, Lohmander LS, Ekdahl C, Beynnon BD. Knee injury and osteoarthritis outcome score (KOOS)--development of a self-administered outcome measure. The Journal of orthopaedic and sports physical therapy. 1998;28:88-96.

20. Bellamy N, Buchanan WW, Goldsmith CH, Campbell J, Stitt LW. Validation study of WOMAC: a health status instrument for measuring clinically important patient relevant outcomes to antirheumatic drug therapy in patients with osteoarthritis of the hip or knee. J Rheumatol. 1988;15:1833-40.

21. Altman R, Brandt K, Hochberg M, Moskowitz R, Bellamy N, Bloch DA, et al. Design and conduct of clinical trials in patients with osteoarthritis: recommendations from a task force of the osteoarthritis research society. Results from a workshop. Osteoarthr Cartil. 1996:4:217-43.

22. Paradowski PT, Bergman S, Sunden-Lundius A, Lohmander LS, Roos EM. Knee complaints vary with age and gender in the adult population. Population-based reference data for the Knee injury and Osteoarthritis Outcome Score (KOOS). BMC Musculoskelet Disord 2006;7:38.

23. Petersson IF, Boegard T, Saxne T, Silman AJ, Svensson B. Radiographic osteoarthritis of the knee classified by the Ahlback and Kellgren \& Lawrence systems for the tibiofemoral joint in people aged 35-54 years with chronic knee pain. Ann Rheum Dis. 1997;56:493-6.

24. Bergman S, Herrstrom P, Hogstrom K, Petersson IF, Svensson B, Jacobsson LT. Chronic musculoskeletal pain, prevalence rates, and sociodemographic associations in a Swedish population study. J Rheumatol. 2001;28:1369-77.

25. Wolfe F, Smythe HA, Yunus MB, Bennett RM, Bombardier C, Goldenberg DL, et al. The American College of Rheumatology 1990 criteria for the classification of fibromyalgia. Report of the multicenter criteria committee. Arthritis Rheum. 1990;33:160-72.

26. Roos EM, Roos HP, Ekdahl C, Lohmander LS. Knee injury and osteoarthritis outcome score (KOOS)--validation of a Swedish version. Scand J Med Sci Sports. 1998:8:439-48

27. Brooks RG, Jendteg S, Lindgren B, Persson U, Bjork S. EuroQol: health-related quality of life measurement. Results of the Swedish questionnaire exercise. Health Policy. 1991;18:37-48.

28. Sullivan M, Karlsson J. The Swedish SF-36 health survey III. Evaluation of criterionbased validity: results from normative population. J Clin Epidemiol. 1998:51:1105-13.

29. Sullivan M, Karlsson J, Ware JE Jr. The Swedish SF-36 health survey--I. evaluation of data quality, scaling assumptions, reliability and construct validity across general populations in Sweden. Soc Sci Med. 1995:41:1349-58.

30. Boegard T, Rudling O, Petersson IF, Jonsson K. Correlation between radiographically diagnosed osteophytes and magnetic resonance detected cartilage defects in the tibiofemoral joint. Ann Rheum Dis. 1998;57:401-7. 
31. Boegard T, Rudling O, Petersson IF, Jonsson K. Correlation between radiographically diagnosed osteophytes and magnetic resonance detected cartilage defects in the patellofemoral joint. Ann Rheum Dis. 1998;57:395-400.

32. Ahlback S. Osteoarthrosis of the knee. A radiographic investigation. Acta Radiol Diagn (Stockh) 1968:Suppl 277:7-72.

33. Croft P, Rigby AS, Boswell R, Schollum J, Silman A. The prevalence of chronic widespread pain in the general population. J Rheumatol. 1993;20:710-3.

34. Mansfield KE, Sim J, Jordan JL, Jordan KP. A systematic review and metaanalysis of the prevalence of chronic widespread pain in the general population. Pain. 2016;157:55-64.

35. Muraki S, Akune T, Nagata K, Ishimoto Y, Yoshida M, Tokimura F, et al. Does osteophytosis at the knee predict health-related quality of life decline? A 3year follow-up of the ROAD study. Clin Rheumatol. 2015;34:1589-97.

36. Kornaat PR, Bloem JL, Ceulemans RY, Riyazi N, Rosendaal FR, Nelissen RG, et al. Osteoarthritis of the knee: association between clinical features and MR imaging findings. Radiology. 2006;239:811-7.

37. Torres L, Dunlop DD, Peterfy C, Guermazi A, Prasad P, Hayes KW, et al. The relationship between specific tissue lesions and pain severity in persons with knee osteoarthritis. Osteoarthr Cartil. 2006;14:1033-40.

38. Sengupta M, Zhang YQ, Niu JB, Guermazi A, Grigorian M, Gale D, et al. High signal in knee osteophytes is not associated with knee pain. Osteoarthr Cartil. 2006:14:413-7.

39. Weiss E. Knee osteoarthritis, body mass index and pain: data from the osteoarthritis initiative. Rheumatology (Oxford). 2014:53:2095-9.

40. Bergman S, Jacobsson LT, Herrstrom P, Petersson IF. Health status as measured by SF-36 reflects changes and predicts outcome in chronic musculoskeletal pain: a 3-year follow up study in the general population. Pain. 2004;108:115-23.

41. Salaffi F, Sarzi-Puttini P, Girolimetti R, Atzeni F, Gasparini S, Grassi W. Healthrelated quality of life in fibromyalgia patients: a comparison with rheumatoid arthritis patients and the general population using the SF-36 health survey. Clin Exp Rheumatol. 2009;27:567-74.

42. Hoffman DL, Dukes EM. The health status burden of people with fibromyalgia: a review of studies that assessed health status with the SF-36 or the SF-12. Int J Clin Pract. 2008;62:115-26.

43. Jiao J, Davis lii JM, Cha SS, Luedtke CA, Vincent A, Oh TH. Association of rheumatic diseases with symptom severity, quality of life, and treatment outcome in patients with fibromyalgia. Scand J Rheumatol. 2015:1-8.

44. Picavet HS, Hoeymans N. Health related quality of life in multiple musculoskeletal diseases: SF-36 and EQ-5D in the DMC3 study. Ann Rheum Dis. 2004;63:723-9.

45. Strand V, Boers M, Idzerda L, Kirwan JR, Kvien TK, Tugwell PS, et al. It's good to feel better but it's better to feel good and even better to feel good as soon as possible for as long as possible. Response criteria and the importance of change at OMERACT 10. J Rheumatol. 2011;38:1720-7.

46. Roos EM, Lohmander LS. The knee injury and osteoarthritis outcome score (KOOS): from joint injury to osteoarthritis. Health Qual Life Outcomes. 2003;1:64.

47. Geenen R, Overman CL, Christensen R, Asenlof P, Capela S, Huisinga KL, et al. EULAR recommendations for the health professional's approach to pain management in inflammatory arthritis and osteoarthritis. Ann Rheum Dis. 2018;77:797-807.

48. Bergman S, Thorstensson CA, Andersson ML. Chronic widespread pain and its associations with quality of life and function at 20 years follow-up in individuals with chronic knee pain at inclusion. Ann Rheum Dis. 2015; 74(suppl):1195.

\section{Publisher's Note}

Springer Nature remains neutral with regard to jurisdictional claims in published maps and institutional affiliations.

Ready to submit your research? Choose BMC and benefit from:

- fast, convenient online submission

- thorough peer review by experienced researchers in your field

- rapid publication on acceptance

- support for research data, including large and complex data types

- gold Open Access which fosters wider collaboration and increased citations

- maximum visibility for your research: over $100 \mathrm{M}$ website views per year

At $\mathrm{BMC}$, research is always in progress.

Learn more biomedcentral.com/submissions 